\title{
Dukungan keluarga, kepatuhan dan pemahaman pasien terhadap diet rendah garam pada pasien dengan hipertensi
}

\author{
Wahid Tri Wahyudi ${ }^{1}$, Risa Herlianita², Deswiyan Pagis ${ }^{3 *}$ \\ 1Program Studi Ilmu Keperawatan Universitas Malahayati Bandar Lampung. Email: nisun.yudi@yahoo.com \\ 2Program Studi IImu Keperawatan Universitas Muhammadiyah Malang. Email: risaherlianita@umm.ac.id \\ 3Puskesmas Gedong Air Kota Bandar Lampung. *Email: pagisdeswiyan@yahoo.com
}

\begin{abstract}
Family support, adherence and understanding of a low-salt diets among patients with hypertensive

Background: Hypertension is a disorder of the blood vessels that results in the supply of oxygen and nutrients carried by the blood blocked to the tissues of the body that needs it. Based on data from the Gedong Air Health Center, it is known that from 2015 to 2018 the incidence of hypertension fluctuated, wherein 2016 it amounted to 1962 cases but in 2017 it increased to 2814 cases and in 2018 the incidence of hypertension was 3102 cases.

Purposes: Knowing the relationship of family support, adherence, and understanding of a low-salt diet among patients with hypertensive

Method: A quantitative research designed with analysis by cross-sectional approach and the population was patients with hypertensive with a sample of 139 as respondents by simple random sampling. Collecting data by questionnaires and Analysing data used Univariate and Bivariate (Chi-Square).

Results: Finding that the patient has negative family support was $58.7 \%$, the patient was noncompliant to a lowsalt diet $.57 .2 \%$, and few patients have an understanding of a low-salt diet. There is a relationship between the understanding of a low-salt diet ( $p$-value $=0.000)$, family support $(p$-value $=0.032)$ and compliance with a low-salt diet among patients with hypertensive.

Conclusion: There is a relationship of understanding of low-salt diets, family support and compliance to a lowsalt diet among patients with hypertensive. Suggestions for health workers in providing health education to families and patients with hypertensive about the importance of low salt diets in the management of hypertension
\end{abstract}

\section{Keywords: Family support; Compliance; Understanding; Low-salt diet; Hypertensive.}

Pendahuluan: Hipertensi merupakan suatu gangguan pada pembuluh darah yang mengakibatkan suplai oksigen dan nutrisi yang dibawa oleh darah terhambat sampai ke jaringan tubuh yang membutuhkanya. Berdasarkan data dari Puskesmas Gedong Air, diketahui bahwa dari tahun 2015 - 2018 kejadian hipertensi mengalami fluktuatif, dimana tahun 2016 sebesar 1962 kasus namun di tahun 2017 mengalami peningkatan menjadi sebesar 2814 kasus dan di tahun 2018 kejadian hipertensi sebesar 3102 kasus.

Tujuan: Diketahui hubungan dukungan keluarga, kepatuhan dan pemahaman pasien terhadap diet rendah garam pada pasien dengan hipertensi

Metode: Penelitian kuantitatif dengan rancangan analitik dan pendekatan cross sectional, populasinya seluruh pasien dengan hipertensi dengan sampel sebanyak 139 dengan simple random sampling. Pengumpulan data dengan kuesioner data dianalisa secara univariate dan bivariate (chi square)

Hasil: Diketahui dukungan keluarga kategori negatif $58,7 \%$, responden tidak patuh $57,2 \%$, dan sedikit yang memiliki pemahaman diet rendah garam ( $p$-value $=0,000)$, ada hubungan antara dukungan keluarga $(p$-value $=$ 0,032 ), kepatuhan dan pemahaman pasien terhadap diet rendah garam pada pasien dengan hipertensi

Simpulan: Ada hubungan dukungan keluarga, kepatuhan dan pemahaman pasien terhadap diet rendah garam pada pasien dengan hipertensi. Saran bagi petugas kesehatan puskesmas dalam memberikan pendidikan kesehatan kepada keluarga dan pasien dengan hipertensi tentang pentingnya diet rendah garam.

Kata Kunci: Dukungan keluarga; Kepatuhan; Pemahaman; Pasien; Diet rendah garam; Hipertensi 
Dukungan keluarga, kepatuhan dan pemahaman pasien terhadap diet rendah garam pada pasien dengan hipertensi

\section{PENDAHULUAN}

Pembangunan kesehatan memiliki tujuan untuk meningkatkan kesadaran, kemauan, dan kemampuan hidup sehat bagi setiap orang agar peningkatan derajat kesehatan masyarakat yang setinggi-tingginya dapat terwujud, sehingga tercipta masyarakat Indonesia yang penduduknya hidup dengan perilaku sehat, memiliki kemampuan untuk menjangkau pelayanan kesehatan yang bermutu secara adil dan merata, serta memiliki derajat kesehatan yang setinggi-tingginya. Berdasarkan tujuan pembangunan tersebut, sektor kesehatan memfokuskan pada upaya mencapai Indonesia Sehat kurun waktu 2015-2019. Salah satu upaya tersebut adalah menanggulangi penyakit tidak menular yakni hipertensi, diabetes, obesitas, kanker dan gangguan jiwa (Kementerian Kesehatan Republik Indonesia, 2016).

Hipertensi gangguan yang terjadi pada pembuluh darah dimana tekanan darah sistolik lebih dari $140 \mathrm{mmHg}$ dan diastolik lebih dari 90 mmHg (Asdie, 2012; Kementerian Kesehatan Republik Indonesia, 2015).

Penderitanya 1 dari 4 orang dewasa di Indonesia menderita hipertensi, namun hanya $1 / 3$ penderita yang melakukan pemeriksaan rutin serta minum obat secara teratur. Keluarga memegang peranan penting untuk memotivasi penderita hipertensi agar rutin memeriksakan tekanan darah, minum obat secara teratur, serta memberikan dukungan dalam mengkonsumsi makanan yang sesuai untuk mencegah terjadinya hipertensi berat yang akan menimbulkan komplikasi (Sari, 2017).

Peningkatan tekanan darah di seluruh dunia, diperkirakan menyebabkan 7,5 juta kematian, sekitar $12,8 \%$ dari total semua kematian. Ini menyumbang 57 juta Disability Adjusted Life Years (DALYS) atau 3,7\% dari total DALYS (World Health Organization, 2017). Tekanan darah tinggi sebagai penyebab utama atau berkontribusi hampir 1.000 kematian setiap hari di Amerika, tekanan darah tinggi meningkatkan risiko kesehatan yang berbahaya seperti sekitar 7 dari setiap 10 orang mengalami serangan jantung, sekitar 8 dari setiap 10 orang mengalami stroke pertama mereka memiliki tekanan darah tinggi, sekitar 7 dari setiap 10 orang dengan gagal jantung kronis dan penyakit ginjal juga merupakan faktor risiko utama untuk tekanan darah tinggi (Centers for Disease Control and Prevention,
2015). Sekitar 972 juta orang atau $26,4 \%$ orang di seluruh dunia mengidap hipertensi, 333 juta berada di negara maju dan 639 sisanya berada di negara berkembang, termasuk Indonesia, angka ini kemungkinan akan meningkat menjadi $29,2 \%$ di tahun 2025 (Yonata, \& Pratama, 2016). Selama 2015-2016, prevalensi hipertensi adalah 29,0\% dan meningkat seiring dengan usia, kelompok usia 18-39 sebesar 7,5\%, kelompok usia 40-59 sebesar $33,2 \%$, dan kelompok usia 60 ke atas sebesar 63,1\% (Fryar, Ostchega, Hales, Zhang, \& Kruszon, 2017).

Prevalensi hipertensi penduduk umur 18 tahun ke atas tahun 2013 sebesar $25,8 \%$ dan di tahun 2018 naik menjadi 34.1\% (Kementerian Kesehatan Republik Indonesia, 2018). Penyakit hipertensi dapat terjadi pada berbagai tahapan usia dengan prevalensi yaitu sebanyak $45,9 \%$ pada usia 55-64 tahun, $57,6 \%$ pada usia $65,74 \%$ dan $63,8 \%$ pada usia 75 tahun (Kementerian Kesehatan Republik Indonesia, 2016).

Diketahui bahwa dari tahun 2015 - 2018 kejadian hipertensi mengalami fluktuatif, dimana tahun 2015 penderita hipertensi sebesar 2173 kasus, di tahun 2016 menurun menjadi sebesar 1962 kasus namun di tahun 2017 mengalami peningkatan menjadi sebesar 2814 kasus dan di tahun 2018 kejadian hipertensi sebesar 3102 kasus (Dinas Kesehatan Kota Bandar Lampung, 2019).

Faktor-faktor yang mempengaruhi terjadinya hipertensi dibagi dalam dua kelompok besar yaitu faktor yang tidak dapat dikendalikan seperti jenis kelamin, umur, genetik, ras dan faktor yang dapat dikendalikan seperti pola makan, kebiasaan olah raga, konsumsi garam, kopi, alkohol dan stres. Untuk terjadinya hipertensi perlu peran faktor risiko tersebut secara bersama-sama (common underlying risk factor), dengan kata lain satu faktor risiko saja belum cukup menyebabkan timbulnya hipertensi (Asdie, 2012).

Hipertensi dapat dikendalikan salah satunya jika pasien termotivasi untuk tetap pada rencana menjalankan diet hipertensi dan dapat dikontrol dengan pengaturan pola makan yang baik. Pasien dapat melaksanakan diet dengan baik apabila didukung dengan mengikuti rekomendasi medis dengan baik dan adanya dukungan keluarga. Rekomendasi medis yang diikuti seseorang, akan mengacu pada persepsi untuk melakukan suatu

Wahid Tri Wahyudi' Program Studi llmu Keperawatan Universitas Malahayati Bandar Lampung.

Email: nisun.yudi@yahoo.com

Risa Herlianita ${ }^{2}$ Program Studi llmu Keperawatan Universitas Muhammadiyah Malang. Email: risaherlianita@umm.ac.id Deswiyan Pagis ${ }^{3 *}$ Puskesmas Gedong Air Kota Bandar Lampung. *Email: pagisdeswiyan@yahoo.com 
Dukungan keluarga, kepatuhan dan pemahaman pasien terhadap diet rendah garam pada pasien dengan hipertensi

perilaku atau sikap dalam menjalankan pelaksanaan kepatuhan diet hipertensi (Brilianifah, \& Isnaeni, 2017). Cara yang paling baik dalam menghindari komplikasi hipertensi adalah dengan mengatur diet / pola makan seperti rendah garam, rendah kolesterol dan lemak jenuh, meningkatkan konsumsi buah dan sayuran (Dasopang, \& Rahayu, 2017).

Kepatuhan diet akan terlaksana dengan baik apabila seseorang tahu akan manfaat yang dapat diambil dan didukung dengan pemahaman yang memadai. Pemahaman yang dimiliki akan menentukan suatu perilaku dan perubahan untuk penyakitnya. Pemahaman yang rendah mengenai kepatuhan diet dapat menurunkan kesadaran dengan pentingnya melaksanakan kepatuhan diet hipertensi dan dapat berdampak atau berpengaruh pada cara pelaksanaan diet hipertensi, akibatnya dapat terjadi komplikasi berlanjut. Kepatuhan diet hipertensi dapat dicapai apabila pasien dapat melaksanakan diet yang diberikan secara teratur atau konsisten (Notoatmodjo, 2014).

Penelitian terdahulu menyimpulkan terdapat hubungan tingkat pemahaman tentang diet dengan kepatuhan diet penderita hipertensi (Dasopang, \& Rahayu, 2017; Hendrawati, 2018).

Faktor lain yang dapat mempengaruhi kepatuhan dengan diet adalah dukungan keluarga. Dukungan keluarga dalam hal ini sangat berperan dalam meningkatkan kepatuhan menjalankan diet yang dianjurkan karena keluarga merupakan unit terdekat dengan pasien. Adanya perhatian dan dukungan dalam mengontrol dan mengingatkan apabila pasien lupa menjalankan diet dengan baik dan merubah gaya hidup sesuai dengan petunjuk medis, dapat mempercepat proses kesembuhan (Brilianifah, \& Isnaeni, 2017).

Bentuk dukungan keluarga yang diberikan dapat berupa dorongan, semangat, pemberian nasehat, kepercayaan dan perhatian. Bentuk dukungan tersebut membuat seseorang memiliki perasaan nyaman, yakin, dipedulikan dan dicintai oleh keluarga sehingga seseorang dapat menghadapi masalah dan melaksanakan kepatuhan diet hipertensi dengan baik (Friedman, Bowden, \& Jones, 2014). Keluarga memiliki peranan penting dalam proses pengawasan, pemeliharaan dan pencegahan terjadinya komplikasi hipertensi di rumah. Selain itu, keluarga juga dapat memberikan dukungan dan membuat keputusan mengenai perawatan yang dilakukan oleh penderita hipertensi (Hendrawati, 2018). Dukungan keluarga berkontribusi sebesar $61,8 \%$ dan mempunyai hubungan sangat kuat dengan kepatuhan, semakin tinggi dukungan keluarga maka semakin tinggi kepatuhan (Yeni, Husna, \& Dachriyanus, 2016; Imran, 2017).

Berdasarkan hasil prasurvei yang dilakukan di Puskesmas Gedong Air pada Februari 2019 diketahui dari 15 penderita hipertensi sebanyak 10 $(66,7 \%)$ penderita hipertensi tidak mengetahui jenis makanan yang tidak boleh dikonsumsi dan sebanyak $13(86,7 \%)$ penderita hipertensi mengungkapkan bahwa keluarga di rumah tetap menyajikan makanan seperti gorengan atau yang bersantan.

\section{METODE PENELITIAN}

Penelitian kuantitatif analitik dengan pendekatan cross sectional, dilaksanakan di wilayah kerja Puskesmas Rawat Inap Gedong Air Kota Bandar Lampung pada Maret - Juni 2019. Populasi seluruh pasien yang mengalami hipertensi, dengan sampel sebanyak 139 responden, dan menggunakan teknik simple random sampling.

Pengumpulan data diperoleh dari sumber langsung (data primer dari responden) dan data diperoleh dari sumber tidak langsung (data sekunder). Sedangkan alat ukur yang digunakan untuk mengumpulkan data berupa kuesioner. Kuesioner kepatuhan diet rendah garam menggunakan kuesioner baku yaitu Dietary Salt Reduction Self-Care Behavior Scale (DSR-SCB scale). Kuesioner tersebut mempunyai nilai CVI (Content Validity Index) $=0,8$ (Sembiring, 2015). Kuesioner terdiri dari 9 pertanyaan yang terdiri dari 5 pilihan jawaban yaitu, tidak pernah, jarang sekali, kadang-kadang, sering dan selalu.

Kuesioner dukungan keluarga berdasarkan analisis reliability didapatkan nilai 0,748-0,954 dan Cronbach's Alpha sebesar 0,972 >0,60 maka test valid dan reliabel, adopsi dari penelitian (Setianingsih, 2017).

Kuesioner pemahaman berdasarkan analisis reliability dengan ini didapatkan nilai $0,568-0,883$ dan r11 spearman-brown coefficient sebesar $0,963>0,60$ maka test valid dan reliabel, adopsi dari penelitian (Nuridayanti, 2016).

Wahid Tri Wahyudi' Program Studi llmu Keperawatan Universitas Malahayati Bandar Lampung.

Email: nisun.yudi@yahoo.com

Risa Herlianita ${ }^{2}$ Program Studi llmu Keperawatan Universitas Muhammadiyah Malang. Email: risaherlianita@umm.ac.id Deswiyan Pagis ${ }^{3 *}$ Puskesmas Gedong Air Kota Bandar Lampung. *Email: pagisdeswiyan@yahoo.com 
HASIL

Tabel.1 Distribusi Frekuensi Responden N=139

\begin{tabular}{lcc}
\hline Variabel & Frekuensi (f) & Persentase (\%) \\
\hline Kepatuhan & & \\
& 59 & 42.8 \\
Patuh & 80 & 57.2 \\
Tidak Patuh & & \\
& & \\
Dukungan Keluarga & 57 & 41.3 \\
Positif & 82 & 58.7 \\
Negatif & & \\
& & \\
Pemahaman & 60 & 43.5 \\
Baik & 79 & 56.5 \\
Buruk & & \\
\hline
\end{tabular}

Berdasarkan tabel 1, diketahui dari 139 responden, sebagian besar tidak patuh terhadap diet rendah garam, yaitu sebanyak $80(57,2 \%)$ responden, sebagian besar mendapat dukungan keluarga kategori negatif sebanyak $82(58,7 \%)$ responden dan sebagian besar mempunyai pemahaman diet rendah garam kategori buruk sebanyak $79(56,5 \%)$ responden.

Tabel 2. Hubungan Dukungan Keluarga, Kepatuhan dan Pemahaman Pasien Terhadap Diet Rendah Garam N=139

\begin{tabular}{|c|c|c|c|c|c|c|c|c|}
\hline \multirow{3}{*}{ Variabel } & \multicolumn{4}{|c|}{ Kepatuhan } & & & \multirow{3}{*}{$p$-value } & \multirow{3}{*}{$\begin{array}{c}\text { OR } \\
\text { CI } 95 \%\end{array}$} \\
\hline & \multicolumn{2}{|c|}{ Patuh } & \multicolumn{2}{|c|}{ Tidak patuh } & \multicolumn{2}{|c|}{ Total } & & \\
\hline & $\mathrm{n}$ & $\%$ & $\mathrm{n}$ & $\%$ & $\mathbf{N}$ & $\%$ & & \\
\hline \multicolumn{9}{|c|}{ Dukungan keluarga } \\
\hline Positif & 31 & 22,3 & 26 & 18,7 & 57 & 41 & 0,032 & $2,257(1,128-4,517)$ \\
\hline Negatif & 28 & 20,2 & 54 & 38,8 & 82 & 59 & & \\
\hline \multicolumn{9}{|c|}{ Pemahaman } \\
\hline Baik & 46 & 33,1 & 14 & 10,1 & 60 & 43,2 & 0,000 & $16,429(7,063-38,211)$ \\
\hline Buruk & 13 & 9,4 & 66 & 47,4 & 79 & 56,8 & & \\
\hline
\end{tabular}

Berdasarkan Tabel 2. dapat diketahui dari 57 responden dengan dukungan keluarga positif, sebanyak $31(22,3 \%)$ responden patuh dan sebanyak $26(18,7 \%)$ responden tidak patuh. Dari 82 responden dengan dukungan keluarga negatif, sebanyak $28(20,2 \%)$ responden patuh dan sebanyak $54(38,8 \%)$ responden tidak patuh. Hasil uji statistik diperoleh $p$-value $=0,032$ yang berarti $p$-value $<a(0,05)$, maka dapat disimpulkan bahwa ada hubungan dukungan keluarga dengan kepatuhan diet rendah garam dengan nilai $O R$ 2,257 berarti responden dengan dukungan keluarga positif memiliki peluang 2,257 kali lebih besar patuh jika dibandingkan dengan responden dengan dukungan keluarga negatif.

Berdasarkan pemahaman responden terhadap diet rendah garam kategori baik, sebanyak 46 $(33,1 \%)$ responden patuh dan sebanyak 14

Wahid Tri Wahyudi' Program Studi llmu Keperawatan Universitas Malahayati Bandar Lampung.

Email: nisun.yudi@yahoo.com

Risa Herlianita ${ }^{2}$ Program Studi llmu Keperawatan Universitas Muhammadiyah Malang. Email: risaherlianita@umm.ac.id Deswiyan Pagis ${ }^{3 *}$ Puskesmas Gedong Air Kota Bandar Lampung. *Email: pagisdeswiyan@yahoo.com 
Dukungan keluarga, kepatuhan dan pemahaman pasien terhadap diet rendah garam pada pasien dengan hipertensi

$(10,1 \%)$ responden tidak patuh. Dari 79 responden dengan pemahaman terhadap diet rendah garam kategori buruk, sebanyak $13(9,4 \%)$ responden patuh dan sebanyak $66(47,4 \%)$ responden tidak patuh. Hasil uji statistik diperoleh $p$-value $=0,000$ yang berarti $p$-value $<a(0,05)$, maka dapat disimpulkan bahwa ada hubungan pemahaman pasien terhadap diet rendah garam dengan kepatuhan diet rendah garam dengan nilai $O R$ 16,429 berarti responden dengan pemahaman terhadap diet rendah garam kategori baik memiliki peluang 16,429 kali lebih besar patuh jika dibandingkan dengan responden dengan pemahaman terhadap diet rendah garam kategori buruk.

\section{PEMBAHASAN}

\section{Distribusi Frekuensi Kepatuhan Pasien}

Berdasarkan hasil penelitian dari 139 responden, sebagian besar tidak patuh terhadap diet rendah garam, yaitu sebanyak $80(57,2 \%)$ responden. Kepatuhan berasal dari kata dasar patuh, yang berarti disiplin dan taat. Kepatuhan sejauh mana perilaku pasien sesuai dengan ketentuan yang diberikan oleh petugas kesehatan (Niven, 2013). Sejalan dengan penelitian sebelumnya bahwa 19 lansia (54,3\%) tidak patuh dalam diet hipertensi dan 16 lansia (45,7\%) patuh dalam diet hipertensi (Kusumastuti, 2014). 100 responden sebanyak 97 responden (97\%) memiliki ketidak patuhan, sedangkan sebanyak 2 responden (2\%) memiliki kepatuhan (Dasopang, \& Rahayu, 2017). Hasil penelitian sebanyak 79 orang $(79.8 \%)$ lansia tidak patuh terhadap diet hipertensi, dan 20 orang (20.2\%) lansia patuh terhadap diet hipertensi (Hendrawati, 2018).

Berdasarkan hasil penelitian diketahui bahwa sedikit responden yang patuh terhadap diet rendah garam, yaitu sebanyak 59 (42,8\%) responden, menurut peneliti kepatuhan pada responden ini bisa terjadi ketika ada faktor yang mempengaruhinya, seperti pemahaman yang baik dan adanya dukungan keluarga sehingga responden mematuhi diet rendah garam, tujuan pengobatan pada penderita hipertensi adalah untuk meningkatkan kualitas hidup, akan tetapi banyak yang berhenti berobat ketika tubuhnya sedikit membaik, sehingga diperlukan kepatuhan pasien yang menjalani pengobatan hipertensi agar didapatkan kualitas hidup pasien yang lebih baik.
Faktor yang mempengaruhi kepatuhan pasien dalam berobat antara lain tingkat pendidikan, tingkat pengetahuan, tingkat penghasilan, kemudahan menuju fasilitas kesehatan dan tersedianya asuransi kesehatan yang meringankan pasien dalam membayar biaya pengobatan namun pada penelitian ini terdapat responden tidak patuh terhadap diet rendah garam, yaitu sebanyak 80 $(57,2 \%)$ responden, hal ini dapat terjadi karena responden belum sepenuhnya mengurangi garam dalam konsumsi dan masih cukup sering untuk mengkonsumsi makanan cepat saji karena praktis dan rasanya lebih gurih jika responden mengkonsumsi makanan dengan jumlah asupan garam yang dibatasi.

Menurut pendapat peneliti kepatuhan diet rendah garam yang benar akan mempengaruhi perubahan tekanan darah. Kepatuhan diet rendah garam yang benar dapat menjaga tekanan darah tetap terkendali. Jika tekanan darah terkendali maka komplikasi hipertensi dapat dihindari. Kepatuhan dapat digunakan sebagai parameter tingkat pengetahuan pasien melakukan diet rendah garam dari tenaga medis yang berupa pengetahuan tentang resep, meminum obat secara teratur dan tepat dan merubah gaya hidup.

\section{Distribusi Frekuensi Dukungan Keluarga}

Berdasarkan hasil penelitian dari 139 responden, sebagian besar dengan dukungan keluarga negatif yaitu sebanyak $82 \quad(58,7 \%)$ responden. Dukungan sebagai tindakan dan penerimaan terhadap seseorang, sepeti dalam keluarga yang bersifat mendukung selalu siap memberikan pertolongan dan bantuan jika diperlukan, dalam hal ini penerima dukungan keluarga akan tahu bahwa ada orang lain yang memperhatikan, menghargai dan mencintainya. Keluarga berperan sebagai sistem pendukung bagi anggotanya (Friedman, Bowden, \& Jones, 2014).

Berdasarkan hasil penelitian diketahui dari 139 responden, hanya sedikit dukungan keluarga kategori positif yaitu sebanyak $57(41,3 \%)$ dan sebagian besar dengan dukungan keluarga negatif yaitu sebanyak $82(58,7 \%)$ responden, hal ini menurut pendapat peneliti pada item pernyataan terkait keluarga tidak mempunyai cukup dana untuk membuatkan menu khusus artinya responden merasa selama ini bahwa keluarga kurang mendukung diet hipertensi karena ada

Wahid Tri Wahyudi' Program Studi llmu Keperawatan Universitas Malahayati Bandar Lampung.

Email: nisun.yudi@yahoo.com

Risa Herlianita ${ }^{2}$ Program Studi llmu Keperawatan Universitas Muhammadiyah Malang. Email: risaherlianita@umm.ac.id Deswiyan Pagis ${ }^{3 *}$ Puskesmas Gedong Air Kota Bandar Lampung. *Email: pagisdeswiyan@yahoo.com 
Dukungan keluarga, kepatuhan dan pemahaman pasien terhadap diet rendah garam pada pasien dengan hipertensi

permasalahan dana yang kurang untuk membuat menu yang berbeda antara penderita hipertensi dengan anggota keluarga lain, dan pada item pernyataan kedekatan keluarga membuat saya dicintai dan disayangi sehingga termotivasi untuk menghindari konsumsi makanan yang mengandung tinggi garam, seperti makanan yang diawetkan, juga memiliki nilai point rendah hal ini terjadi kemungkinan kurangnya kedekatan antar anggota keluarga yang bisa dikarenakan kurangnya pengetahuan keluarga terkait penyakit hipertensi sehingga keluarga tidak memberikan perhatian yang lebih terhadap penderita hipertensi.

Menurut pendapat peneliti keluarga dapat berperan sebagai sistem pendukung bagi anggotanya. Anggota keluarga juga berpandangan bahwa orang yang bersifat mendukung selalu siap memberikan pertolongan dan bantuan jka diperlukan.

\section{Distribusi Frekuensi Pemahaman Pasien}

Berdasarkan hasil penelitian dari 139 responden, sebagian besar dengan pemahaman buruk yaitu sebanyak $79(56,5 \%)$ responden. Pemahaman tentang diet rendah garam tak seorang pun dapat mematuhi diet rendah garam jika ia salah paham tentang diet rendah garam yang diberikan padanya. Lebih dari $60 \%$ yang diwawancarai setelah bertemu dengan dokter salah mengerti tentang diet rendah garam yang diberikan pada mereka (Niven, 2013). Pengetahuan yang dimiliki seseorang sangat berpengaruh dalam menyikapi suatu permasalahan yang ada, sehingga mampu menghasilkan keputusan yang tepat. Pengetahuan dipengaruhi oleh faktor internal dan eksternal (Notoatmodjo, 2014).

Berdasarkan hasil penelitian diketahui bahwa hasil penelitian dari 139 responden, sebagian dengan pemahaman baik yaitu sebanyak 60 $(43,5 \%)$ responden dimana terlihat responden memahami bahwa rendah garam merupakan salah satu cara mengatasi hipertensi tanpa efek samping selain itu responden juga memahami bahwa tujuan diet rendah garam adalah untuk menurunkan tekanan darah artinya responden memahami terkait manfaat dan tujuan dari diet rendah garam namun sebagian besar dengan pemahaman buruk yaitu sebanyak $79(56,5 \%)$ responden hal ini dapat terlihat pada item pertanyaan penting untuk membaca nilai gizi sebelum mengonsumsi makanan/ minuman, seperti minuman kemasan yang mengandung tinggi natrium/garam memiliki nilai point rendah, hal ini terjadi karena responden belum memahami pentingnya untuk membaca nilai gizi dari setiap makanan yang di konsumsi karena responden belum memahami lebih dalam perjalanan penyakit hipertensi tersebut sebagian besar responden hanya memahami bahwa tujuan diet rendah garam untuk menurunkan tekanan darah dan menurunkan berat badan bagi yang obesitas, responden tidak memahami dampak kelebihan garam dalam tubuh. Menurut pendapat peneliti pemahaman terhadap diet rendah garampada hakikatnya adalah suatu kegiatan atau usaha untuk menyampaikan pesan kesehatan kepada masyarakat, kelompok atau individu.

\section{Hubungan Dukungan Keluarga, Kepatuhan dan Pemahaman Pasien Terhadap Diet Rendah Garam}

Keluarga berfungsi sebagai sistem pendukung bagi anggotanya dan anggota keluarga memandang bahwa orang yang bersifat mendukung, selalu siap memberikan pertolongan dan bantuan jika diperlukan. Keluarga dapat menjadi faktor yang sangat mempengaruhi dalam menentukan keyakinan dan nilai kesehatan individu serta dapat menentukan tentang program pengobatan yang dapat mereka terima (Friedman, Bowden, \& Jones, 2014). Salah satu faktor yang mempengaruhi kepatuhan pengoabatan adalah adanya peran keluarga (Niven, 2013).

Berdasarkan hasil penelitian diketahui dari 57 responden dengan dukungan keluarga positif, sebanyak $31(22,3 \%)$ responden patuh hal ini sejalan dengan teori yang mengungkapkan bahwa dengan dukungan keluarga yang positif maka dapat meningkatkan kepatuhan seseorang, Dukungan keluarga terdekat akan mempengaruhi sikap, tindakan dan penerimaan terhadap klien yang berfungsi sebagai sistem pendukung bagi anggotanya. Keluarga akan memandang bahwa orang yang bersifat mendukung selalu siap memberikan pertolongan dengan bantuan jika diperlukan dan sebanyak $26(18,7 \%)$ responden tidak patuh hal ini dimungkinkan adanya faktor lain seperti pemahaman yang buruk terkait tentang konsumsi garam harian bagi penderita hipertensi atau adanya motivasi responden yang buruk

Wahid Tri Wahyudi' Program Studi llmu Keperawatan Universitas Malahayati Bandar Lampung.

Email: nisun.yudi@yahoo.com

Risa Herlianita ${ }^{2}$ Program Studi llmu Keperawatan Universitas Muhammadiyah Malang. Email: risaherlianita@umm.ac.id

Deswiyan Pagis ${ }^{3 *}$ Puskesmas Gedong Air Kota Bandar Lampung. *Email: pagisdeswiyan@yahoo.com 
Dukungan keluarga, kepatuhan dan pemahaman pasien terhadap diet rendah garam pada pasien dengan hipertensi

sehingga responden terkadang tidak mematuhi asupan makan yang seharusnya di konsumsi untuk penderita hipertensi, sehingga diperlukan peran petugas dalam upaya promotif terkait dengan kepatuhan ini sehingga penderita hipertensi benarbenar dapat memahi dan mematuhi konsumsi garam harian bagi dirinya.

Berdasarkan hasil penelitian diketahui dari 82 responden dengan dukungan keluarga negatif, sebanyak $28(20,2 \%)$ responden patuh hal ini dimungkinkan adanya faktor lain seperti responden memahami diet rendah garam bagi dirinya sehingga walaupun tidak di dukung oleh keluarga namun responden memiliki pemahaman dan motivasi yang baik sehingga responden patuh terhadap konsumsi garam harian atau karena adanya dukungan dari petugas kesehatan sehingga responden mematuhi diet yang di sarankan dan sebanyak 54 (38,8\%) responden tidak patuh, menurut pendapat peneliti bahwa peran dari keluarga sangat berharga dan akan menambah kepatuhan dalam diet rendah garam.

Menurut pendapat peneliti adanya hubungan dukungan keluarga dengan kepatuhan diet dapat terjadi karena faktor dukungan keluarga menjadikan keluarga berfungsi sebagai pendukung pengetahuan responden, sehingga akan meningkatkan kesehatan dan adaptasi responden dalam kehidupan.

Berdasarkan hasil penelititian diketahui dari 60 responden dengan pemahaman terhadap diet rendah garambaik, sebanyak $46(33,1 \%)$ responden patuh menurut peneliti pengetahuan penderita hipertensi dapat menjadi guru yang baik bagi dirinya, dengan adanya pengetahuan yang dimilikinya akan mempengaruhi tingkat kepatuhan pengobatan hipertensi. Penderita hipertensi yang memiliki pengetahuan tentang hipertensi yang tinggi akan lebih cenderung patuh dari pada penderita hipertensi yang memiliki pengetahuan yang rendah. Menurut pendapat peneliti pemahaman terhadap diet rendah garam berhubungan dengan kepatuhan diet rendah garam. Pemahaman terhadap diet rendah garam dapat merubah pengetahuan, sikap, maupun perilaku sehat, selain itu permahaman terhadap diet rendah garam merupakan upaya persuasi agar pasien mau melakukan tindakan untuk memelihara dan meningkatkan kesehatan namun masih terdapat sebanyak $14(10,1 \%)$ responden tidak patuh, hal ini dimungkinkan adanya dukungan keluarga yang negatif sehingga menyebabkan responden tidak patuh, dukungan tersebut antara lain keluarga tidak memiliki cukup dana untuk menyiapkan menu khusus penderita hipertensi sehingga penderita hipertensi mengkonsumsi makanan yang sama dengan anggota keluarga lain. Dari 79 responden dengan pemahaman terhadap diet rendah garam kategori buruk, sebanyak $13(9,4 \%)$ responden patuh hal ini dimungkinkan adanya faktor lain seperti adanya dukungan dari petugas kesehatan sehingga responden mematuhi apa yang disarankan oleh petugas kesehatan dan sebanyak $66 \quad(47,4 \%)$ responden tidak patuh, menurut pendapat peneliti pengetahuan tidak hanya didapat secara formal melainkan melalui pengalaman.

\section{SIMPULAN}

Diketahui sebagian besar dengan pemahaman kategori buruk yaitu sebanyak $79(56,8 \%)$ responden. Diketahui sebagian besar dengan dukungan keluarga negatif yaitu sebanyak 82 (59\%) responden. Ada hubungan dukungan keluarga dengan kepatuhan diet rendah garam ( $p$-value $=0,032$ OR 2,257). Ada hubungan hubungan pemahaman pasien terhadap diet rendah garam dengan kepatuhan diet rendah garam 019 ( $p$-value $=0,000$ OR 16,429).

\section{SARAN}

Diharapkan perawat dapat memberikan pendidikan kesehatan kepada keluarga dan pasien hipertensi tentang diet rendah garam secara maksimal sehingga dapat menurunkan kejadian hipertensi di wilayah kerja Puskesmas, serta melakukan promosi kesehatan baik dalam bentuk poster, banner, leaflet, baligo tentang konsep kepatuhan maupun konsep kesehatan lainnya.

\section{DAFTAR PUSTAKA}

Asdie, A. H. (2012). Harrison: Prinsip-prinsip IImu Penyakit Dalam. Jakarta: EGC.

Brilianifah, Y. N., \& Isnaeni, F. N. (2017). Hubungan pengetahuan dan dukungan keluarga terhadap kepatuhan diet hipertensi pada pasien hipertensi rawat jalan di RSU Queen Latifa Sleman Yogyakarta (Doctoral dissertation, Universitas Muhammadiyah Surakarta).

Centers for Disease Control and Prevention. (2015). High blood pressure facts. See http://www. cdc. gov/bloodpressure/facts.htm.

Dasopang, E. S., \& Rahayu, R. G. (2017). Hubungan Tingkat Pengetahuan Tentang Diet Dengan

Wahid Tri Wahyudi' Program Studi llmu Keperawatan Universitas Malahayati Bandar Lampung.

Email: nisun.yudi@yahoo.com

Risa Herlianita ${ }^{2}$ Program Studi llmu Keperawatan Universitas Muhammadiyah Malang. Email: risaherlianita@umm.ac.id Deswiyan Pagis ${ }^{3 *}$ Puskesmas Gedong Air Kota Bandar Lampung. *Email: pagisdeswiyan@yahoo.com 
Dukungan keluarga, kepatuhan dan pemahaman pasien terhadap diet rendah garam pada pasien dengan hipertensi

Kepatuhan Diet Penderita Hipertensi di Puskesmas Padang Bulan. Jurnal Sains dan Teknologi Farmasi, 19(Supl1), s11-s16.

Dinas Kesehatan Kota Bandar Lampung. (2019) . Profil kesehatan Puskesmas Gedong Air. Bandar Lampung.

Friedman, M. M., Bowden, V. R., \& Jones, E. G. (2014). Buku Ajar Keperawatan keluarga: Riset, Teori, dan Praktek. Jakarta: EGC.

Fryar, C. D., Ostchega, Y., Hales, C. M., Zhang, G., \& Kruszon, M. D. (2017). Hypertension Prevalence and Control Among Adults: United States, 20152016. NCHS data brief, (289), 1-8.

Hendrawati, I. A. (2018). Hubungan Pengetahuan Dengan Kepatuhan Diet Hipertensi Pada Lansia Di Kampung Honje Luhur Kelurahan Sukagalih Wilayah Kerja Pkm Pembangunan Kecamatan Tarogong Kidul Kabupaten Garut Tahun 2017. Jurnal Kesehatan Bakti Tunas Husada: Jurnal IImu-ilmu Keperawatan, Analis Kesehatan dan Farmasi, 18(1), 105-112.

Imran, A. (2017). Hubungan dukungan keluarga dengan kepatuhan pengendalian hipertensi pada lansia di Puskesmas Pandak 1 Bantul Yogyakarta (Doctoral dissertation, STIKES Jenderal Achmad Yani Yogyakarta).

Kementerian Kesehatan Republik Indonesia. (2015). Pusat data dan informasi: Hipertensi. Jakarta: Kementerian Kesehatan RI.

Kementerian Kesehatan Republik Indonesia. (2016). Pusat data dan informasi Profil Kesehatan Indonesia 2015. Kementerian Kesehatan Rl, Jakarta.

Kementerian Kesehatan Republik Indonesia. (2018). Riset Kesehatan Dasar 2018. Jakarta: Kementerian Kesehatan RI.

Kusumastuti, D. I. (2014). Hubungan pengetahuan dengan kepatuhan diet hipertensi pada lansia yang mengalami hipertensi di Panti Wredha Dharma Bakti Kasih Surakarta. Surakarta: STIKES Kusuma Husada.

Niven, N. (2013). Psikologi Kesehatan Dan IImu Perilaku. Jakarta: EGC.

Notoatmodjo, S. (2014). Kesehatan Masyarakat IImu dan Seni. Jakarta: Rineka Cipta.

Nuridayanti, A. (2016). Pengaruh edukasi diet dan terapi obat terhadap pengetahuan, perilaku diet dan kepatuhan minum obat penderita hipertensi di pos pembinaan Terpadu Kelurahan Mojoroto Kota Kediri Jawa Timur tesis.

Sari, Y. N. I. (2017). Berdamai dengan hipertensi. Jakarta: Bumi Medika.

Sembiring, E. (2015). Hubungan antara kepatuhan diet rendah garam, kepatuhan minum obat, riwayat hipertensi dengan kejadian rehospitalisasi pada pasien gagal jantung kongestif (Master's thesis).

Setianingsih, D. R. (2017). Hubungan dukungan keluarga dengan kepatuhan diet hipertensi pada lansia (Studi Di Dusun Mojongapit Desa Mojongapit Kecamatan Jombang Kabupaten Jombang) (Doctoral dissertation, STIKES Insan Cendekia Medika Jombang).

World Health Organization. (2017). Global Health Observatory (GHO) data Raised blood pressure Situation and trends.

Yeni, F., Husna, M., \& Dachriyanus, D. (2016). Dukungan Keluarga Memengaruhi Kepatuhan Pasien Hipertensi. Jurnal Keperawatan Indonesia, 19(3), 137-144.

Yonata, A., \& Pratama, A. S. P. (2016). Hipertensi sebagai Faktor Pencetus Terjadinya Stroke. Jurnal Majority, 5(3), 17-21.

Wahid Tri Wahyudi' Program Studi llmu Keperawatan Universitas Malahayati Bandar Lampung.

Email: nisun.yudi@yahoo.com

Risa Herlianita ${ }^{2}$ Program Studi llmu Keperawatan Universitas Muhammadiyah Malang. Email: risaherlianita@umm.ac.id

Deswiyan Pagis ${ }^{3 *}$ Puskesmas Gedong Air Kota Bandar Lampung. *Email: pagisdeswiyan@yahoo.com 